\title{
Prevalence of and risk factors for age-related macular degeneration in Nepal: the Bhaktapur Retina Study
}

This article was published in the following Dove Press journal:

Clinical Ophthalmology

22 May 2017

Number of times this article has been viewed

\author{
Raba Thapa' \\ Sanyam Bajimaya' \\ Govinda Paudyal' \\ Shankar Khanal ${ }^{2}$ \\ Stevie $\operatorname{Tan}^{3}$ \\ Suman S Thapa' \\ Ger van Rens ${ }^{3}$ \\ 'Vitreo-retina Service, Tilganga \\ Institute of Ophthalmology, \\ Kathmandu, ${ }^{2}$ Central Departments \\ of Statistics, Tribhuvan University, \\ Kirtipur, Nepal; ${ }^{3}$ Department of \\ Ophthalmology, Vrije University \\ Medical Center, Amsterdam, \\ the Netherlands
}

Aim: This study aimed to explore the prevalence of and risk factors for age-related macular degeneration (AMD) in an elderly population in Nepal.

Subjects and methods: This is a population-based, cross-sectional study. A sample size of 2,100 was calculated. A total of $1,860(88.6 \%)$ subjects aged $>60$ years were enrolled for the study from 30 clusters in the district. Detailed history, visual acuity, and anterior segment and posterior segment examinations were performed. AMD was graded according to the International ARM Epidemiological Study Group.

Results: Among the total study population, 659 subjects had any AMD (35.43\%; 95\% confidence interval [CI]: 33.25-37.65), 484 had mild dry AMD (26.02\%; 95\% CI: 24.04-28.08), 143 had intermediate dry AMD (7.69\%; 95\% CI: 6.52-8.99), 19 had geographic atrophy $(1.02 \%$; 95\% CI: $0.61-1.59)$, and 13 had wet AMD (0.70\%; 95\% CI: 0.37-1.19). The overall prevalence of early and late AMD was $33.71 \%$ and $1.72 \%$, respectively. Among subjects with dry and wet AMD , 36.53\% and $46.1 \%$ had visual impairment, while $2.78 \%$ and $23.08 \%$ were blind, respectively. In multivariate analysis, AMD was significantly higher in subjects with an increased number of cigarettes smoked per day (odds ratio [OR] 1.02, 95\% CI: $1.01-1.04 ; P=0.007$ ) and in subjects with pseudophakia (OR 1.45, 95\% CI: $1.12-1.87$; $P=0.005$ ).

Conclusion: One-third of the population aged $\geq 60$ years have some form of AMD. There was a significant association with the number of cigarettes consumed and with previous cataract surgery.

Keywords: age-related macular degeneration, prevalence, risk factors, Nepal

\section{Introduction}

Age-related macular degeneration (AMD) is an emerging public health problem in the developing world due to rapid increases in the aging population. ${ }^{1-3}$ AMD is the most common cause of irreversible blindness in the developed world among elderly people, ${ }^{4-9}$ and it is the third leading cause of global blindness, contributing to $8.7 \%$ of the total blindness in the world. ${ }^{1}$ Population-based studies in developed countries have shown a prevalence of AMD between $9.1 \%$ and $20.9 \% .^{4,5,7-9}$ In developing countries, its prevalence is between $3.1 \%$ and $10.6 \% .{ }^{10-15}$ AMD was among the leading causes of blindness in Nepal, contributing to $8.7 \%$ of the total blindness in a population-based study. ${ }^{16}$ Retinal disease was the second most common cause of blindness, and among the retinal diseases, AMD was the most prevalent form of retinal disease. ${ }^{17,18}$ Although the wet variety of AMD constitutes only $10 \%$ of total AMD, it is the main cause of irreversible blindness. ${ }^{19}$ Besides non-modifiable risk factors such as age and genetic predisposition, $5,6,13,20-24$ there are several studies that have reported modifiable risk
Vitreo-retina Service, Tilganga Institute of Ophthalmology, PO Box 56I,

Gaushala, Kathmandu, Nepal

Tel +977 | 4493775

Fax +977 | 4474937

Email rabathapa@live.com
Clinical Ophthalmology 2017:1 I 963-972

(c) (1) (8) ( ) 2017 Thapa et al. This work is published and licensed by Dove Medical Press Limited. The full terms of this license are avalable at https://www.dovepress.com/terms.php

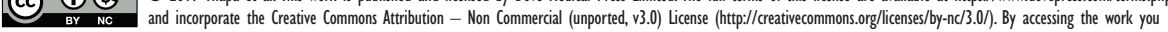
hereby accept the Terms. Non-commercial uses of the work are permitted without any further permision from Dove Medical Press Limited, provided the work is properly attributed. For permision

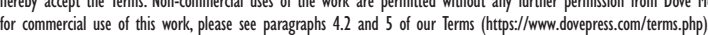


factors for AMD, such as sun exposure, smoking, systemic hypertension, and dietary habits..$^{20,21,25-35}$ More complete identification of these risk factors could help reduce the burden of visual impairment from AMD.

The 2011 census has shown an increase in the life expectancy of the Nepalese population. ${ }^{36}$ This is expected to increase the prevalence of age-related diseases such as AMD in Nepal. This is the first study to estimate the prevalence and risk factors of AMD in the Nepali population.

\section{Subjects and methods Study population}

Bhaktapur district has two municipalities and 161 village development committees. According to the 2001 census, the population of Bhaktapur was 298,704, and 48,223 people were older than 40 years. In the Bhaktapur Glaucoma Study (BGS), a World Health Organization (WHO) 30 cluster sampling method was used. ${ }^{17,37}$ From these 30 clusters, a houseto-house enumeration was done and a name list was prepared. From this name list, 4,800 subjects older than 40 years were selected using the Epi Info software, version 3.5.1. ${ }^{17}$ From these 4,800 subjects, only those older than 60 years were re-invited for an examination. The total sample size of the Bhaktapur Retina Study (BRS) was 2,100 with subjects older than 60 years. This comprised $62 \%$ of the total sample of those older than 60 years of the BGS. Of the remaining $38 \%, 15 \%$ of the subjects had passed away, $5 \%$ had moved to other places, and $18 \%$ were unable to visit the study site. The required sample size for this BRS was estimated to be 2,100 subjects after assuming 7\% prevalence for vitreoretinal disorders in individuals at the age of 60 years or older, a relative precision of $25 \%, 85 \%$ compliance, and a design effect of $2 .{ }^{18}$ Since we were not able to include a sufficient number of participants from the original BGS participating clusters, we added extra clusters in a similar pattern to this study. In order to meet the calculated sample size of 2,100, the rest (38\%) were selected from the adjoining clusters as a cross-sectional survey. Two female community health workers visited the subjects at their homes and invited them to participate in the study. All subjects were referred to the primary eye care center of Bhaktapur district for a detailed evaluation. Complete information was available in $1,860(86.57 \%)$ subjects. The study was conducted from August 2013 to December 2015.

A structured questionnaire was developed to assess the prevalence of and risk factors for AMD. Mid-level ophthalmic personnel were involved in the interview, and two ophthalmologists were involved in the examination of the study subjects. A total of 50 cases were pre-tested. No respondents reported difficulties in answering the questionnaire, and there were no statistically significant variations in examination findings. When the subjects were able to read and write in the national language, they were categorized as literate as defined by the Government of Nepal. The predominant profession was considered as the occupation.

\section{Patient examination and AMD assessment}

All patients underwent a detailed history; anterior segment assessment, including measurement of intraocular pressure; and dilated fundus examination. The best-corrected visual acuity (BCVA) was assessed using the logarithm of minimum angle of resolution ( $\log \mathrm{MAR}$ ) with tumbling $\mathrm{E}$ charts placed at $4 \mathrm{~m}$. Two retina specialists performed standardized eye examinations on the patients. A total of five fundus photographs were taken of each eye after mydriasis using a digital fundus camera (Canon) by a trained mid-level ophthalmic technician who had obtained a government-certified course to provide primary eye care in ophthalmology.

Visual impairment was based on the International Classification of Diseases, 10th edition. ${ }^{38}$ Briefly, visual impairment was defined as visual acuity (VA) $<6 / 18$ $(<20 / 60,<0.3 \operatorname{logMAR})$ in the better eye with best correction. Visual impairment was subcategorized between low vision and blindness. Low vision was defined as a BCVA of $<6 / 18(<20 / 60,<0.3 \log$ MAR $)$ but not $<3 / 60$ $(20 / 400,1.5 \log \mathrm{MAR})$ in the better eye. A BCVA of $<3 / 60$ $(<20 / 200,<1.5 \log$ MAR $)$ with best correction in the better eye was considered as blindness.

AMD was graded according to the international classification developed by the International ARM Epidemiological Study Group on clinical examination. ${ }^{39}$ Briefly, age-related maculopathy (ARM) is a degenerative disorder in individuals $\geq 50$ years of age characterized by the presence of the following abnormalities in the macula: soft drusen $\geq 63 \mu \mathrm{m}$, hyperpigmentation and/or hypopigmentation of the retinal pigment epithelium (RPE), RPE and associated neurosensory detachment, (peri) retinal hemorrhage, geographic atrophy of the RPE, or (peri) retinal fibrous scarring in the absence of other retinal (vascular) disorders. VA is not used to define the presence of ARM. Drusen were defined as discrete round whitish-yellow spots external to the neuroretinal pigment epithelium or RPE in the macula. The largest drusen determined the grade for maximum drusen size and predominant drusen type. The type was based on the size of drusen, uniformity of appearance across the breadth, and the sharpness of edges. Drusen were categorized as small if the diameter was $<64 \mu \mathrm{m}$, 
intermediate if the diameter was 64-124 $\mu \mathrm{m}$, and large if the diameter was $>125 \mu \mathrm{m} .{ }^{40}$ Based on boundaries, drusen were categorized as hard, soft, or confluent. Hard drusen were discrete and well demarcated, soft drusen were amorphous and poorly demarcated, and confluent drusen had contiguous boundaries between drusen. Hard drusen were small, usually $<63 \mu \mathrm{m}$ in diameter, although some may be larger, round, pale yellowish white spots. Soft distinct drusen were defined by a size $\geq 250 \mu \mathrm{m}$ with sharp margins and round, nodular appearance with a uniform density (color) from the center to periphery. Soft indistinct drusen were of the same size as soft distinct drusen but had indistinct margins and a softer, less solid appearance. Pigmentary abnormalities included either increased pigmentation or hypopigmentation of the RPE more sharply demarcated than drusen, without any visibility of associated choroidal vessels. Geographic atrophy was defined as any sharply delineated round or oval area of hypopigmentation or depigmentation or any apparent absence (at least $175 \mu \mathrm{m}$ in size) of the RPE in which choroidal vessels are more visible than the vessels in the surrounding areas. Dry AMD was defined as the presence of drusen and RPE abnormalities, including geographic atrophy. Dry AMD was categorized as mild, intermediate, and advanced AMD. Mild dry AMD was characterized by the presence of many small drusen or a few intermediate drusen. Intermediate dry AMD was characterized by the presence of many intermediate-sized drusen and at least one large-sized drusen. Advanced AMD was characterized by the presence of geographic atrophy. Early AMD was defined as the presence of 63-125 $\mu \mathrm{m}$ drusen with the presence of hyper/hypopigmentation or $\geq 125 \mu \mathrm{m}$ drusen with or without the presence of hyper/hypopigmentation and no signs of late AMD. Late AMD was defined by the presence of any of the following: geographic atrophy or pigment epithelial detachment, subretinal hemorrhage or visible subretinal new vessels, subretinal fibrotic scar or laser treatment scar, or a history of photodynamic or anti-vascular endothelial growth factor treatment for AMD. ${ }^{6}$

Similarly, the study subjects were also divided into five groups according to the size and extent of drusen in each eye, presence of geographic atrophy, and neovascular changes in AMD. ${ }^{30}$ The five groups were numbered sequentially based on the increasing severity of drusen and type of AMD. They were defined as follows: Group 1 (normal), each eye had no drusen or non-extensive small drusen; Group 2 (intermediate drusen), at least one eye had one or more intermediate drusen, extensive small drusen, or pigment abnormalities associated with AMD; Group 3 (large drusen), at least one eye had one or more large drusen or extensive intermediate drusen; Group 4 (geographic atrophy), at least one eye had geographic atrophy with a diameter of at least one-eighth that of the optic disk; and Group 5 (neovascular), choroidal neovascularization or an RPE detachment in one eye (nondrusenoid RPE detachment, serous or hemorrhagic retinal detachment, subretinal hemorrhage, subretinal pigment epithelial hemorrhage, subretinal fibrosis, or evidence of confluent photocoagulation for neovascular AMD).

\section{Assessment and definitions of risk factors}

A detailed history was taken using a standardized questionnaire. All subjects underwent blood examination for nonfasting blood sugar, and measurements of blood pressure (BP), height, weight, and abdominal girth were recorded. Age, gender, education status, occupation, smoking, alcohol consumption, sunlight exposure, and presence of systemic problems such as diabetes mellitus, hypertension, hyperlipidemia, or other cardiac disorders were elicited from the self-reported history. Body weight and height were measured using standard techniques, and body mass index (BMI) was calculated by the formula BMI = weight in kilograms divided by the square of the height in meters $\left(\mathrm{kg} / \mathrm{m}^{2}\right)$. Similarly, abdominal girth was measured using a standardized technique. Venous blood sample was drawn for assessment of non-fasting blood sugar. The diagnosis of diabetes mellitus was based on either the use of diabetic medications or a random blood sugar level of $\geq 200 \mathrm{mg} / \mathrm{dL} .^{18,41} \mathrm{BP}$ was measured for all subjects. They were categorized as hypertensive if systolic BP was $\geq 140 \mathrm{mmHg}$, diastolic BP was $\geq 90 \mathrm{mmHg}$, or antihypertensive medications were used.

The study was approved by the institutional review board and ethics committee of Tilganga Institute of Ophthalmology (TIO) and conducted in accordance with the Declaration of Helsinki. Informed consent was written in the vernacular and was read out for those unable to read. Subjects were asked to sign the consent form, and thumb impressions were taken for those unable to sign prior to enrollment in the study.

\section{Statistical analysis}

Descriptive statistical measures such as mean \pm SD for continuous variables and percentages were computed, respectively, for continuous and categorical variables. Prevalence of different grades of AMD with $95 \%$ confidence interval (CI) was also computed. Associations between AMD (early vs late) were examined through the use of chi-square or Fisher's exact tests wherever applicable. Risk factors for AMD were assessed by using multiple logistic regression analysis followed by univariate analysis, considering the presence of 
AMD as an outcome variable. All results were considered significant if there was a $P$-value $<0.05$. Statistical analyses were performed using Stata 9.0 (StataCorp, College Station, TX, USA).

\section{Results}

Complete information was available for 1,860 (88.57\%) subjects out of 2,100 subjects. The nonresponder and responder groups were compared with regard to age and gender. There was no considerable difference observed for age and gender between the two groups (Table 1).

The characteristics of the study population at various stages of AMD are shown in Table 2. The age ranged from 60 to 95 years with the mean age of $69.64 \pm 7.31$ years. Half of the subjects $(51.08 \%)$ were between 60 and 69 years of age, whereas $11.45 \%$ were of $\geq 80$ years. There were more females, 1,039 (55.86\%), who participated in the study. Among the total, 1,433 (77.04\%) were illiterates and 1,351 (72.63\%) were farmers by occupation. Overall, AMD was found in 659 study subjects (35.43\%; 95\% CI: 33.25-37.65), of whom 484 subjects $(26.02 \%$; 95\% CI: 24.04-28.08) had mild dry AMD (Group 2). There were 143 subjects with intermediate dry AMD (Group 3; 7.69\%; 95\% CI: 6.52-8.99), 19 with geographic atrophy (Group 4; 1.02\%; 95\% CI: 0.61-1.59), and 13 with wet AMD (Group 5; 0.70\%; 95\% CI: 0.37-1.19). The distributions of various stages of AMD were similar in all age groups. The proportions of advanced stages of AMD were higher with increasing age. The distributions of various stages of AMD among the study subjects were comparable between genders, between the illiterates and literates, and between farmers and individuals with other occupations. Almost two-thirds of total AMD subjects had mild dry AMD.

Table 3 shows the prevalence and laterality of dry and wet AMD among the study subjects. Among the total subjects with AMD, the majority had dry AMD (34.73\%; 95\% CI: 32.56-36.94), while wet AMD comprised 0.70\% (95\% CI: 0.37-1.19) of subjects. There was bilateral involvement in $63.13 \%$ of all AMD subjects (95\% CI: 59.31-66.82).

Table I Comparison of responders and nonresponders in the study population

\begin{tabular}{llll}
\hline Variable & $\begin{array}{l}\text { Responders } \\
(\mathbf{n}=1, \mathbf{8 6 0})\end{array}$ & $\begin{array}{l}\text { Nonresponders } \\
(\mathbf{n}=\mathbf{2 4 0})\end{array}$ & P-value \\
\hline $\begin{array}{l}\text { Age (years), } \\
\text { mean } \pm \text { SD }\end{array}$ & $69.64 \pm 7.31$ & $69.50 \pm 7.93$ & 0.782 \\
$\begin{array}{l}\text { Male, n (\%) } \\
\text { Female, n (\%) }\end{array}$ & $\begin{array}{l}\text { 82I (44.14) } \\
\text { I,039 (55.86) }\end{array}$ & $\begin{array}{l}110(45.83) \\
130(54.17)\end{array}$ & 0.629 \\
\hline
\end{tabular}

This pattern of bilateral involvement (62.54\%) was similar among the subjects with dry AMD, whereas it was much higher among the subjects with wet AMD (92.31\%).

Table 4 shows the characteristics of study subjects with early and late-stage AMD. Among the subjects with AMD, 627 had early AMD (95.14\%; 95\% CI: 93.21-96.65), whereas 32 had late-stage AMD (4.86\%; 95\% CI: 3.34-6.78).

Late AMD was significantly higher $(P=0.001)$ among pseudophakic subjects as compared to early AMD. Late AMD was higher among the subjects aged 60-69 years $(5.59 \%)$ and $\geq 80$ years $(7.32 \%)$ as compared to those aged 70-79 years (3.14\%). Similarly, there was no significant difference between early and late AMD subjects with regard to gender, literacy, or occupation. Past and present smokers had a higher rate of late AMD as compared to nonsmokers, but this difference was not significant statistically. The amount of smoking ranged from 1 to 40 cigarettes per day with the mean of $8.21 \pm 6.78$. A higher number of cigarettes smoked

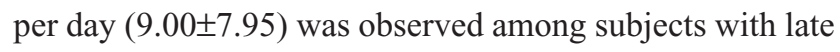
AMD as compared to early AMD (8.17 \pm 6.73$)$.

Similarly, late AMD was higher among present drinkers relative to past drinkers and non-drinkers. Advanced AMD was higher among the hypertensive subjects as compared to those without hypertension, whereas it was lower among the subjects with diabetes mellitus than those without diabetes mellitus, but these differences were not statistically significant either. Late AMD was higher among those with a BMI $<24.9 \mathrm{~kg} / \mathrm{m}^{2}$ as compared to those with a BMI $>25 \mathrm{~kg} / \mathrm{m}^{2}$. In our series, late AMD was higher among the subjects with myopia, while all subjects with hypermetropia had early AMD.

Among the subjects with AMD, 623 (94.54\%) reported that they never use sun protection measures (using hat, sunglasses, or both or seeking shade when outside in bright light), and $593(95.18 \%)$ of them had early stage AMD. Only four (0.61\%) subjects with AMD reported high levels of protection (at least $50 \%$ of the time using sun protection measures), and $32(4.86 \%)$ subjects were using low-to-moderate protection (rarely to various patterns of use in sunlight).

Figure 1 shows the visual status based on BCVA. Among the study subjects, low vision and blindness were found in $34.89 \%$ and $1.17 \%$ of subjects, respectively, among those not having AMD. Among the subjects with dry AMD, 36.53\% subjects had low vision and $2.78 \%$ were blind, whereas among the subjects with wet AMD, 46.18\% subjects had low vision and $23.08 \%$ were blind.

Table 5 lists the risk factors for AMD in univariate analysis. The risk of AMD was significantly higher $(P=0.025)$ 
Table 2 Demographic characteristics of study subjects across various groups of AMD

\begin{tabular}{|c|c|c|c|c|c|c|}
\hline Characteristics & $\begin{array}{l}\text { All study } \\
\text { subjects } \\
(\mathrm{n}=\mathrm{I}, 860) \\
\mathrm{n}(\%)\end{array}$ & $\begin{array}{l}\text { Group I: } \\
\text { no AMD }(n=I, 20 I) \text {, } \\
\text { n, \% }(95 \% \mathrm{Cl})\end{array}$ & $\begin{array}{l}\text { Group 2: } \\
\text { mild dry AMD } \\
(\mathrm{n}=484), \mathrm{n}, \% \\
(95 \% \mathrm{Cl})\end{array}$ & $\begin{array}{l}\text { Group 3: } \\
\text { intermediate dry } \\
\text { AMD }(n=\mid 43) \text {, } \\
n, \%(95 \% \mathrm{Cl})\end{array}$ & $\begin{array}{l}\text { Group 4: } \\
\text { geographic } \\
\text { atrophy }(n=19) \text {, } \\
n, \%(95 \% \mathrm{Cl})\end{array}$ & $\begin{array}{l}\text { Group 5: } \\
\text { wet AMD } \\
(n=13), n, \% \\
(95 \% \mathrm{Cl})\end{array}$ \\
\hline \multicolumn{7}{|l|}{ Age (years) } \\
\hline $60-69$ & $950(51.08)$ & $628,66.11(63-69)$ & $23 \mathrm{I}, 24.32(22-27)$ & $73,7.68(6-9)$ & II, I.I6 (0.57-0.06) & $7,0.74(0.29-\mid .5 I)$ \\
\hline $70-79$ & $697(37.47)$ & $442,63.4 \mathrm{I}(60-67)$ & $195,27.98(25-31)$ & $52,7.46(6-10)$ & $4,0.57(0.01-1)$ & $4,0.57(0.01-1)$ \\
\hline$\geq 80$ & $213(11.45)$ & $|3|, 6 \mid .50(55.00-68.00)$ & $58,27.23(21-34)$ & $18,8.45(5-13)$ & $4,1.88(0.05-5)$ & $2,0.94(0.01-33)$ \\
\hline \multicolumn{7}{|l|}{ Gender } \\
\hline Male & $821(44.14)$ & $536,65.29(62.00-68.00)$ & $210,25.58(23-29)$ & $61,7.43(6-9)$ & $8,0.97(0.04-2)$ & $6,0.73(0.02-1)$ \\
\hline Female & $\mathrm{I}, 039(55.86)$ & $665,64.00(6 \mathrm{I}-67)$ & $274,26.37(24-29)$ & $82,7.89(6-10)$ & II, I.06 (0.52-I.88) & $7,0.67(0.27-1.38)$ \\
\hline \multicolumn{7}{|l|}{ Occupation } \\
\hline Agriculture & I,35I (72.63) & $855,63.29(6 I-66)$ & $368,27.24(25-30)$ & $104,7.70(6.33-9.25)$ & $13,0.96(0.05-1)$ & $\mathrm{II}, 0.8 \mathrm{I}(0.04-\mathrm{I})$ \\
\hline Others & $509(27.37)$ & $346,67.98(64-72)$ & $116,22.79(19-27)$ & $39,7.66(5-10)$ & $6,1.18(0.04-2)$ & $2,0.39(0.00-1)$ \\
\hline \multicolumn{7}{|l|}{ Literacy } \\
\hline Illiterate & I,433 (77.04) & $920,64.20(62-67)$ & $376,26.24(24-28)$ & II $2,7.82$ (6-9) & $14,0.98(0.53-1.63)$ & II, $0.77(0.03-13)$ \\
\hline Literate & $427(22.96)$ & $28 I, 65.81(6 I-70)$ & $108,25.29(21-30)$ & $31,7.26(4.98-10.14)$ & $5,1.17(0.38-2.7 \mathrm{I})$ & $2,0.47(0.05-1.68)$ \\
\hline
\end{tabular}

Abbreviations: AMD, age-related macular degeneration; $\mathrm{Cl}$, confidence interval.

Table 3 Prevalence and laterality of dry and wet AMD in study subjects

\begin{tabular}{|c|c|c|c|}
\hline AMD types & Prevalence, $\mathrm{n}, \%(95 \% \mathrm{Cl})$ & Unilateral, n, \% (95\% Cl) & Bilateral, $\mathrm{n}, \%(95 \% \mathrm{Cl})$ \\
\hline All AMD & $659,35.43(33.25-37.65)$ & $243,36.87(33.18-40.68)$ & $416,63.13(59.31-66.82)$ \\
\hline Dry AMD & $646,34.73(32.56-36.94)$ & $242,37.46(33.72-41.32)$ & $404,62.54(56.67-66.28)$ \\
\hline Wet AMD & $13,0.70(0.37-1.19)$ & I, $7.69(0.19-36.03)$ & $|2,92.3|$ (63.97-99.80) \\
\hline
\end{tabular}

Abbreviations: AMD, age-related macular degeneration; $\mathrm{Cl}$, confidence interval.

Table 4 Participant characteristics in early and late AMD among subjects with AMD

\begin{tabular}{|c|c|c|c|c|}
\hline Characteristics & Early AMD $(n=627)$ & Late AMD $(n=32)$ & Total, n (\%) & $P$-value \\
\hline \multicolumn{5}{|l|}{ Smoking habit, n, \% (95\% Cl) } \\
\hline Nonsmokers & $277,96.18$ (93.26-98.07) & II, $3.82(1.92-6.73)$ & $288(43.70)$ & 0.526 \\
\hline Present smokers & I72, $93.99(8.94-9.69)$ & $\mathrm{II}, 6.01(3.03-10.50)$ & $183(27.77)$ & \\
\hline Past smokers & I78, $94.68(90.43-97.42)$ & $10,5.32(2.57-9.56)$ & $188(28.53)$ & \\
\hline Cigarettes per day (mean $\pm \mathrm{SD}$ ) & $8.17 \pm 6.73$ & $9.00 \pm 7.95$ & $8.21 \pm 6.78$ & 0.634 \\
\hline \multicolumn{5}{|l|}{ Alcohol consumption, n, \% (95\% Cl) } \\
\hline No alcohol & $260,96.65(93.74-98.45)$ & $9,3.35(1.54-6.25)$ & $269(40.82)$ & 0.147 \\
\hline Present alcohol & $28 I, 93.36(89.92-95.89)$ & $20,6.64(4.10-10.07)$ & $30 I(45.68)$ & \\
\hline Past alcohol & $86,96.63(90.46-99.29)$ & $3,3.37(0.70-9.53)$ & $89(|3.5|)$ & \\
\hline \multicolumn{5}{|l|}{ Hypertension, n, \% (95\% Cl) } \\
\hline Non-hypertensive cases & $402,95.26(92.77-97.08)$ & $20,4.74(2.91-7.22)$ & $422(64.03)$ & 0.852 \\
\hline Hypertensive cases & $225,94.94(91.32-97.35)$ & $12,5.06(2.64-8.67)$ & $237(35.97)$ & \\
\hline Cases without diabetes, n, \% (95\% Cl) & $575,95.20(93.17-96.76)$ & $29,4.80(3.23-6.82)$ & $604(91.65)$ & 0.829 \\
\hline Cases with diabetes, $\mathrm{n}, \%(95 \% \mathrm{Cl})$ & $52,94.55(84.87-98.86)$ & $3,5.45(1.13-15.12)$ & $55(8.35)$ & \\
\hline $\mathrm{BMI} \leq 24.9 \mathrm{~kg} / \mathrm{m}^{2}, \mathrm{n}, \%(95 \% \mathrm{Cl})$ & $381,94.54$ (91.85-96.54) & $22,5.46(3.45-8.14)$ & $403(61.15)$ & 0.366 \\
\hline $\mathrm{BMI} \geq 25 \mathrm{~kg} / \mathrm{m}^{2}, \mathrm{n}, \%(95 \% \mathrm{Cl})$ & $246,96.09(92.93-98.11)$ & $10,3.91(1.88-7.06)$ & $256(38.85)$ & \\
\hline Abdominal girth, $\mathrm{cm}($ mean $\pm \mathrm{SD})$ & $80.86 \pm|2.3|$ & $79.37 \pm 11.65$ & $80.79 \pm 12.27$ & 0.504 \\
\hline Myopia, n, \% (95\% Cl) & $63,92.65(83.66-97.56)$ & $5,7.35(2.43-16.33)$ & $68(10.32)$ & 0.062 \\
\hline Hypermetropia, n, \% (95\% Cl) & $86,100(83.66-97.56)$ & 0,0 & $86(13.05)$ & \\
\hline Others, n, \% (95\% Cl) & $478,94.65(92.31-96.44)$ & $27,5.35(3.55-7.68)$ & $505(76.63)$ & \\
\hline Phakic cases, n, \% (95\% Cl) & $520,96.47(94.55-97.86)$ & $19,3.53(2.13-5.45)$ & $539(81.79)$ & 0.001 \\
\hline Pseudophakic cases, n, \% (95\% Cl) & $107,89.17(82.18-94.10)$ & I3, $10.83(5.89-17.81)$ & $120(18.29)$ & \\
\hline
\end{tabular}

Abbreviations: AMD, age-related macular degeneration; $\mathrm{Cl}$, confidence interval; $\mathrm{BMI}$, body mass index. 


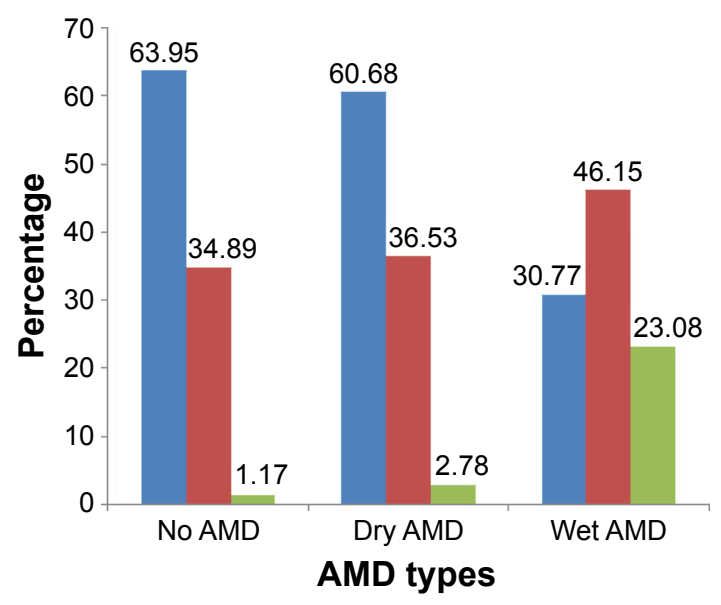

Normal Low vision Blindness

Figure I Visual status based on BCVA among the study subjects.

Abbreviations: BCVA, best-corrected visual acuity; AMD, age-related macular degeneration. with increased frequency of smoking per day. Similarly, there was a high risk of AMD $(P=0.006)$ among those who had undergone a cataract surgery relative to phakic subjects. The odds of developing AMD increased with age. Females had an increased risk of AMD as compared to males. Illiterates, subjects with hypertension, nondiabetic subjects, subjects with BCVA $>0.3 \operatorname{logMAR}$, myopic subjects, subjects with pseudophakia, subjects who consume alcohol, subjects who are not aware of ARMD, or subjects with a BMI $<24.9 \mathrm{~kg} / \mathrm{m}^{2}$ had a higher risk of AMD, but none of these were statistically significant in univariate analysis.

As in the univariate analysis, when multivariate analysis was performed, only two variables, cigarettes per day and pseudophakia, were significant variables. The odds of having AMD were significantly higher with the increasing number of cigarettes smoked per day (odds ratio [OR] 1.02,

Table 5 Risk factors for AMD using logistic regression analysis

\begin{tabular}{|c|c|c|c|c|}
\hline Characteristics & No AMD $(n=I, 20 I)$ & AMD $(n=659)$ & OR (95\% Cl) & $P$-value \\
\hline \multicolumn{5}{|l|}{ Age (years), n (\%) } \\
\hline $60-69$ & $628(66.11)$ & 322 (33.89) & I & \\
\hline $70-79$ & $442(63.4 I)$ & 255 (36.59) & $1.12(0.92-1.38)$ & 0.258 \\
\hline$\geq 80$ & $|3|(6 \mid .50)$ & $82(38.50)$ & $1.22(0.89-1.66)$ & 0.203 \\
\hline \multicolumn{5}{|l|}{ Gender, n (\%) } \\
\hline Male & $536(65.29)$ & 285 (34.7I) & I & \\
\hline Female & $665(64.00)$ & $374(36.00)$ & $1.06(0.87-1.28)$ & 0.566 \\
\hline \multicolumn{5}{|l|}{ Occupation, n (\%) } \\
\hline Agriculture & 855 (63.29) & 496 (36.7I) & $\mathrm{I}$ & 0.06 \\
\hline Other occupations & $346(67.98)$ & I,639 (32.02) & $0.81(0.65-1.01)$ & \\
\hline \multicolumn{5}{|l|}{ Literacy, n (\%) } \\
\hline Illiterate & $920(64.20)$ & $513(35.80)$ & I & \\
\hline Literate & $28 I(65.8 I)$ & $146(34.19)$ & $0.93(0.74-1.17)$ & 0.542 \\
\hline \multicolumn{5}{|l|}{ Hypertension, n (\%) } \\
\hline No & 795 (65.32) & $422(34.68)$ & 1 & \\
\hline Yes & $406(63.14)$ & $237(36.86)$ & $1.10(0.90-1.34)$ & 0.349 \\
\hline \multicolumn{5}{|l|}{ Diabetes, n (\%) } \\
\hline No & I,088 (64.30) & $604(35.70)$ & I & \\
\hline Yes & $1,139(67.26)$ & $55(32.74)$ & $0.88(0.62-1.23)$ & 0.445 \\
\hline \multicolumn{5}{|l|}{ Smoking, n (\%) } \\
\hline Nonsmoker & $524(64.53)$ & $288(35.47)$ & I & \\
\hline Smoker & $677(64.60)$ & $371(35.40)$ & $0.99(0.82-1.2 I)$ & 0.976 \\
\hline Cigarettes per day, (mean \pm SD) & $7.19 \pm 5.63$ & $8.21 \pm 6.78$ & $1.03(1.01-1.05)$ & 0.025 \\
\hline \multicolumn{5}{|l|}{ Alcohol, n (\%) } \\
\hline No alcohol & $525(66.12)$ & $269(33.88)$ & I & \\
\hline Alcohol & $676(63.4 I)$ & $390(36.59)$ & $1.13(0.93-1.36)$ & 0.228 \\
\hline \multicolumn{5}{|l|}{ AMD awareness, $n(\%)$} \\
\hline Yes & $74(71.84)$ & $29(28.16)$ & I & \\
\hline No & I, I $27(64.14)$ & $630(35.86)$ & $\mathrm{I} .43(0.92-2.2 \mathrm{I})$ & 0.114 \\
\hline Myopia, n (\%) & $119(63.64)$ & $68(36.36)$ & I & \\
\hline Hypermetropia, n (\%) & $163(65.46)$ & $86(34.54)$ & $0.92(0.62-1.37)$ & 0.693 \\
\hline Others, $\mathrm{n}(\%)$ & $619(64.54)$ & $505(35.46)$ & $0.96(0.70-1.32)$ & 0.809 \\
\hline \multicolumn{5}{|l|}{ Pseudophakia, n (\%) } \\
\hline No & $\mathrm{I}, 040(65.86)$ & $539(34.14)$ & I & \\
\hline Yes & $161(57.30)$ & $120(42.70)$ & $1.44(1.11-1.86)$ & 0.006 \\
\hline
\end{tabular}

Abbreviations: AMD, age-related macular degeneration; $\mathrm{OR}$, odds ratio; $\mathrm{Cl}$, confidence interval. 
95\% CI: 1.01-1.04; $P=0.007)$. Similarly, the risk of developing AMD was significantly higher among subjects with pseudophakia as compared to phakic subjects (OR 1.45, 95\% CI: $1.12-1.87 ; P=0.005)$.

\section{Discussion}

This is the first population-based study in Nepal to assess the prevalence, patterns, and risk factors of AMD. The BGS had reported AMD to be the most common retinal disease in this population. ${ }^{18}$ There are several other studies in the region that have also reported AMD as the most common retinal disease. ${ }^{14,15}$ Therefore, it is not unexpected for us to report AMD as the most common cause of retinal disease in this population. Population statistics in Nepal have shown that life expectancy over the past 20 years has increased from 53.5 and 55 years to 69.6 and 67.3 years in females and males, respectively. ${ }^{36}$ Improved health facilities and availability of better nutrition, water systems, and vaccination programs could have possibly been responsible. ${ }^{42}$

The overall prevalence of AMD was calculated for a study population older than 60 years in our study, as the BGS did not show a high prevalence of retinal diseases in the 40-60 age group. In the BGS, the prevalence of AMD was 3.5\%, which is lower than that in our study $(35.43 \%)$, presumably caused by our exclusion of the lower age groups. ${ }^{18}$

The overall prevalence of any AMD was 35.43\% in our study subjects, which was higher than that in other studies conducted in the region. ${ }^{7,10,15,25}$ A study conducted by Woo et $\mathrm{al}^{2}$ from China also reported a lower prevalence of $10.6 \%$ in a comparable age group; however, they studied a population $\geq 50$ years old. The higher prevalence of AMD in our study could probably be due to the older age of our subjects. Other possible factors contributing to this could be the prolonged exposure to sunlight during farming and social habits such as smoking and alcohol consumption.

Almost two-thirds of the AMD subjects had small- to intermediate-sized drusen and RPE pigmentary abnormalities, which did not affect the vision. Large-sized drusen were present in $7.69 \%$ of subjects, presumably conferring on them an increased risk for progression to advanced AMD. Geographic atrophy was found in $1.02 \%$ of the study subjects, and wet AMD was present in $0.70 \%$ of the study subjects. A study in south India that focused on an age group of $\geq 60$ years from rural and urban areas reported early AMD in 20.91\% and $16.37 \%$ of subjects, respectively. The same study also reported prevalence of late AMD in $2.26 \%$ of the rural population and $2.32 \%$ of the urban population. ${ }^{13}$ The findings of the abovementioned study are comparable to our study, and the slight differences in rates could be attributed to regional and racial differences.

The Asian Malay Study reported that early and late AMD occurred in $4.9 \%$ and $0.7 \%$ of subjects, respectively, in the age group between 40 and 80 years. ${ }^{43}$ Kawasaki et al ${ }^{44}$ also reported a pooled prevalence of $6.8 \%$ and $0.56 \%$, respectively, for early and late AMD in Asians aged 40-79 years. Other studies from India, a neighboring country to Nepal, reported late AMD in the range of $0.6 \%-1.4 \% .^{10,15} \mathrm{Com}-$ pared to these Asian studies, our finding of late AMD is very similar despite the differences in the study age groups. On the other hand, for early AMD, the differences can be attributed to the age groups studied and different classification systems.

Racial variation in the prevalence of AMD cannot be disregarded. Several studies conducted among white populations have shown a higher prevalence of late AMD than that in our study. ${ }^{4-9}$ Caucasians are more susceptible to AMD. ${ }^{24}$ This has been reported by several studies in the past. ${ }^{4-9,22,30,45-47}$ When compared to these studies, our findings of late AMD are lower. Yasuda et $\mathrm{al}^{21}$ have also reported lower incidence of late AMD among Japanese as compared to white populations. This suggests that racial variation can occur.

The majority of our study population had the dry type of AMD (98.03\%), while the wet variety comprised only $1.97 \%$ of subjects. In a study by Kawasaki et al, ${ }^{12} 30.8 \%$ of Asians had bilateral disease compared to $45.1 \%$ of Caucasians. In a study by Wang et al, ${ }^{48}$ bilateral involvement was seen in $80 \%$ of those with early ARM and 57\% of those with late AMD. In our study population, almost two-thirds of the subjects with any type of AMD had bilateral involvement. A large percentage $(92 \%)$ of the subjects with wet AMD had bilateral involvement. Bilateral involvement is a serious public health concern, as wet AMD can progress rapidly, leading to irreversible visual impairment and blindness.

Early detection of wet AMD is important because it is often characterized by painless, progressive loss of vision without any other ocular signs or symptoms. Amsler grid tests have been advised for high-risk groups for detection of early symptoms of wet AMD. There is a serious need for promoting awareness regarding the disease in the community and rapid access to an ophthalmologist in cases of disturbed vision. A very low level of awareness of AMD was reported in a population-based study conducted on the same cohort, which reflects an urgent need for increasing awareness in the community. ${ }^{49}$

Both early and late AMD increases with age. The number of subjects with late AMD was higher than those with early 
AMD in the more elderly age group. Our findings were comparable to other population-based studies. ${ }^{5,13,21,23,25}$ More than half of the total subjects with geographic atrophy and wet AMD were found in the age group of 60-69 years. This shows that in our population, significant numbers of AMD occur at a relatively early age.

Ho et $\mathrm{al}^{50}$ reported that cataract surgery increases the chances of having dry AMD, and its risk of progression should be considered before recommending cataract surgery. Similarly, Krishnaiah et a ${ }^{25}$ from India reported significant associations of AMD with cataracts and cataract surgery. In our study, we found that late AMD was significantly higher among the pseudophakics. Further analysis of our population is recommended to clarify if there is an effect of cataract surgery on the risk of progression to advanced AMD or a relationship between cataract and AMD.

Late AMD was more common among present smokers and those who consume more cigarettes per day, which is consistent with other studies. ${ }^{21,26-29}$

Hypertension could be an important systemic risk factor for progression of late $\mathrm{AMD}$, as there were higher proportions of late AMD among the hypertensive subjects in our study, which was similar to other studies..$^{20,21,25,27,30}$ Late AMD was lower among the subjects with diabetes. This may be due to a protective effect of diabetes against AMD, which has also been reported by Shim et $\mathrm{al}^{27}$ and Krishnaiah et al. ${ }^{25}$ Present drinkers had more late-stage AMD than those who never drank or past drinkers. This finding suggests that present alcohol consumption could be an important factor for AMD progression as in other studies. ${ }^{27}$ Myopia was found in late AMD subjects, while hypermetropia was found in early AMD subjects of this study. Our findings are consistent with the results from Lavanya et al ${ }^{51}$ who reported an association of hypermetropia with early AMD, and similar findings were seen for Asian eyes. ${ }^{44}$

In our series, there was no difference in the distribution of patients with early and late AMD considering gender, level of literacy, or occupation. Unlike our findings, Yasuda et $\mathrm{al}^{21}$ found late AMD significantly higher among males. Cackett et $\mathrm{al}^{29}$ reported that a lower education level was associated with significantly higher rates of early AMD among Asian Malay.

Visual impairment and blindness were higher among the subjects with wet AMD as compared to those not having AMD or with dry AMD. Low vision among the subjects with dry and wet AMD was $36.53 \%$ and $46.15 \%$, respectively. Likewise, blindness was $2.78 \%$ and $23.08 \%$, respectively, among the subjects with dry and wet AMD. This finding suggests that vision impairment caused by wet AMD can be prevented by early detection and treatment. In subjects with dry AMD without central geographic atrophy, vision is usually preserved. A previous study reported AMD as the most common cause of visual impairment and blindness among pseudophakic subjects and the second most common cause of visual impairment and blindness among phakic subjects, after cataract. ${ }^{52}$ Another population-based study in Nepal reported AMD as a significant cause of blindness, accounting for $8.7 \%$ of all blind eyes. ${ }^{16}$ Globally, AMD has been the third leading cause of blindness, contributing to $8.7 \%$ of total blindness, while also being the most common cause of irreversible blindness among the elderly in developed countries. These findings suggest that AMD is likely the leading cause of irreversible blindness in developing countries where life expectancy is on the rise.

In this study, $95.58 \%$ of subjects had never used sun protection measures such as hats, sun glasses, or both. Among these subjects, $4.82 \%$ had late AMD, and only $0.4 \%$ reported wearing protective measures. Sunlight exposure has been reported as a significant risk factor for AMD. ${ }^{28,34,35}$ Raising awareness and adopting protective measures could help reduce the risk of AMD. In this study, the risk of AMD was dependent on the number of cigarettes smoked per day. This finding was similar to many other studies both from developed and developing countries. ${ }^{6,13,21,25,28,30,47}$

Similarly, there was a significantly higher risk of AMD among those who underwent cataract surgery relative to those who had not, which is consistent with other studies. ${ }^{25,32,33}$ However, there is an ongoing controversy regarding cataract surgery as a risk factor for AMD.

The prevalence of AMD was related to increasing age. Our finding is consistent with other studies from both developed and developing countries. ${ }^{5,6,13,20-23,25}$ Females had an increased risk of AMD as compared to males in this study..$^{13,23,30}$

Similarly, subjects with hypertension had a higher chance of developing AMD, although this was not statistically significant. Our finding is consistent with other series across the globe where hypertension was significantly associated with AMD. ${ }^{20,25,27,30,31}$ Similarly, a higher risk of AMD among illiterates may be associated with lack of using sun protection measures, poor nutrition, and consumption of more cigarettes and alcohol. The increased risk of developing AMD among those who consume alcohol in this study is consistent with other studies. ${ }^{26}$

Unlike other studies where AMD was seen more frequently in those having high $\mathrm{BMI},{ }^{30}$ we found a high rate of 
AMD among the subjects with lower BMI $\left(<24.9 \mathrm{~kg} / \mathrm{m}^{2}\right)$. We are unable to explain the reason for this finding.

Even though there were a large number of subjects with hypermetropia among those with early AMD, which was similar to other studies, ${ }^{23,47,48}$ this was not found to be a risk factor for overall AMD. Myopia was more frequent than hypermetropia and other refractive errors among all subjects with AMD; however, none of these differences were found to be significant.

The risk of AMD was lower among the subjects with diabetes mellitus in this study, similar to other studies..$^{13,27}$

The prevalence of AMD was higher among those who were not aware of AMD (95.6\%), which suggests that promoting awareness for early detection and treatment can lessen the public health burden of AMD. Similarly, promoting awareness of modifiable risk factors, such as protection from sunlight exposure, diet, and healthy social habits, can help prevent the onset of AMD. By providing information regarding the risk factors, healthy nutritional habits, and immediate referral to an ophthalmologist in cases of metamorphopsia or blurred central vision can prevent blindness from this disease.

The strength of the study is the large sample size of the elderly age group. The limitation of the study is that it was not able to comment on the prevalence and risk factors of AMD in a younger population.

\section{Conclusion}

Almost one-third of subjects aged $\geq 60$ years have some form of AMD among the population of Bhaktapur in Nepal. Significant associations with the number of cigarettes consumed and pseudophakia are similar to other reports from around the world. Gender, education status, hypertension, alcohol consumption, and refractive error could be other risk factors for AMD in this population. Regular screening could facilitate early detection of the disease. The low awareness and high prevalence of AMD suggest an urgent need for promoting awareness in the community to motivate people to come in for regular eye examinations. This can help prevent the irreversible visual impairment and blindness from AMD.

\section{Acknowledgments}

We would like to acknowledge Tilganga Institute of Ophthalmology, Kathmandu, Nepal, and Vrije University Medical Center, Amsterdam, the Netherlands, for funding of this study. Likewise, we would like to acknowledge all the patients who participated in this study and the Bhaktapur
Municipality. Professor Paul S Bernstein, MD, PhD, of the Moran Eye Center of the University of Utah, USA, edited the manuscript.

\section{Disclosure}

The authors report no conflicts of interest in this work.

\section{References}

1. Resnikoff S, Pascolini D, Etya'ale D, et al. Global data on visual impairment in the year 2002. Bull World Health Organ. 2004;82(11): 844-851.

2. Woo JH, Sanjay S, Eong KGA. The epidemiology of age-related macular degeneration in the Indian Subcontinent. Acta Ophthalmol. 2009;87(3):262-269.

3. AuEong KG. Age related macular degeneration: an emerging challenge for eye care and public health professionals in the Asia pacific region. Ann Acad Med Singapore. 2006;35(3):133-135.

4. Mitchell P, Smith W, Attebo K, Wang JJ. Prevalence of age-related maculopathy in Australia. The Blue Mountains Eye Study. Ophthalmology. 1995;102(10):1450-1460.

5. Klein R, Klein BE, Linton KL. Prevalence of age-related maculopathy. The Beaver Dam Eye Study. Ophthalmology. 1992;99:933-943.

6. Klein R, Cruickshanks KJ, Nash SD, et al. The prevalence of agerelated macular degeneration and associated risk factors: the Beaver Dam Offspring Study. Arch Ophthalmol. 2010;128(6):750-758.

7. Cruickshanks KJ, Hamman RF, Klein R, et al. The prevalence of age related maculopathy by geographic region and ethnicity. The ColoradoWisconsin Study of age-related maculopathy. Arch Ophthalmol. 1997; 115(2):242-250.

8. Björnsson OM, Syrdalen P, Bird AC, Peto T, Kings B. The prevalence of age-related maculopathy (ARM) in an urban Norwegian population: the Oslo Macular Study. Acta Ophthalmol Scand. 2006;84(5):636-664.

9. Vingerling JR, Dielemans I, Hofman A, et al. The prevalence of agerelated maculopathy in the Rotterdam Study. Ophthalmology. 1995; 102(2):205-210.

10. Gupta SK, Murthy GV, Morrison N, et al. Prevalence of early and late age-related macular degeneration in a rural population in northern India: the INDEYE Feasibility Study. Invest Ophthalmol Vis Sci. 2007;48(3):1007-1011.

11. Krishnaiah S, Das T, Nirmalan PK, et al. Risk factors for age-related macular degeneration: findings from the Andhra Pradesh Eye Disease Study in South India. Invest Ophthalmol Vis Sci. 2005;46(12):4442-4449.

12. Kawasaki R, Wang JJ, Amirul FM, et al. Is bilateral age-related macular degeneration less common in Asians than Caucasians? Ophthalmic Epidemiol. 2011;18(6):253-258.

13. Raman R, Pal SS, Ganesan S, Gella L, Vaitheeswaran K, Sharma T. The prevalence and risk factors for age-related macular degeneration in rural-urban India, Sankara Nethralaya Rural-Urban Age-related Macular Degeneration Study, Report No. 1. Eye. 2016;30(5):688-697.

14. Hatef E, Fotouhi H, Mohammad K, Jalali KH. Prevalence of retinal diseased and their pattern in Tehran. The Tehran Eye Study. Retina. 2008;28(5):755-762.

15. Nirmalan PK, Robin AL, Katz J, et al. Prevalence of vitreoretinal disorders in a rural population of southern India: the Aravind Comprehensive Eye Study. Arch Ophthalmol. 2004;122(4):581-586.

16. Sapkota YD, Pokharel GP, Nirmalan PK, Dulal S, Maharjan IM, Prakash K. Prevalence of blindness and cataract surgery in Gandaki Zone, Nepal. Br J Ophthalmol. 2006;90(4):411-416.

17. Thapa SS, Rana PP, Twyana SN, et al. Rational, methods and baseline demographics of the Bhaktapur Glaucoma Study. Clin Experiment Ophthalmol. 2011;39(2):126-134.

18. Thapa SS, Thapa R, Paudyal I, et al. Prevalence and pattern of vitreoretinal disorders in Nepal: the Bhaktapur Glaucoma Study. BMC Ophthalmol. 2013;13:9. 
19. Bressler NM. Early detection and treatment of neovascular age related macular degeneration. J Am Board Fam Pract. 2002;15(2):142-152.

20. Klein R, Klein B, Tomany SC, Cruickshanks KJ. The association of cardiovascular disease with the long-term incidence of age-related maculopathy. Ophthalmology. 2003;110(6):1273-1280.

21. Yasuda M, Kiyohara $Y$, Hata $Y$, et al. Nine-year incidence and risk factors for age-related macular degeneration in a defined Japanese population the Hisayama Study. Ophthalmology. 2009;116(11): 2135-2140.

22. Van Newkirk MR, Nanjan MB, Wang JJ, Mitchell P, Taylor HR, Mc Carty CA. The prevalence of age-related maculopathy: the visual impairment project. Ophthalmology. 2000;107(8):1593-1600.

23. Chaine G, Hullo A, Sahel J, et al. Case-control study for the risk factors for age related macular degeneration. Br J Ophthalmol. 1998; 82:996-1002.

24. Chakravarthy U, Mc Kay GJ, de Jong PT, et al. ARMS2 increases the risk of early and late age-related macular degeneration in the European Eye Study. Ophthalmology. 2013;120(2):342-348.

25. Krishnaiah S, Das TP, Kovai V, Rao GN. Associated factors for agerelated maculopathy in the adult population in Southern India: the Andhra Pradesh Eye Disease Study. Br J Ophthalmol. 2009;93(9): 1146-1150.

26. Chong EW, Kreis AJ, Wong TY, Simpson JA, Guymer RH. Alcohol consumption and the risk of age-related macular degeneration: a systemic review and metaanalysis. Am J Ophthalmol. 2008;145(4):707-715.

27. Shim SH, Kim SG, Bae JH, Yu HG, Song SJ. Risk factors for progression of early age-related macular degeneration in Koreans. Ophthalmic Epidemiol. 2016;23(2):80-87.

28. Armstrong RA, Mousavi M. Overview of risk factors for age-related macular degeneration. J Stem Cells. 2015;10(3):171-191.

29. Cackett P, Wong TY, Aung T, et al. Smoking, cardiovascular risk factors, and age-related macular degeneration in Asians: the Singapore Malay Eye Study. Am J Ophthalmol. 2008;146(6):960-967.

30. Age-related Eye Disease Study Research Group. Risk factors associated with age-related macular degeneration: a case-control study in the Age-related Eye Disease Study: Age-related Eye Disease Study Report Number 3. Ophthalmology. 2000;107(12):2224-2232.

31. Van LR, Ikram MK, Vingerling JR, Witteman JCM, Hofman A, de Jong PTVM. Blood pressure, atherosclerosis, and the incidence of age-related maculopathy. The Rotterdam Eye Study. Invest Ophthalmol Vis Sci. 2003;44:3771-3777.

32. Klein R, Klein BE, Wong TY, et al. The association of cataract and cataract surgery with the long term incidence of age-related maculopathy: the Beaver Dam Eye Study. Arch Ophthalmol. 2002;120(11): 1551-1558.

33. Wang JJ, Klein R, Smith W, et al. Cataract surgery and the 5-year incidence of late stage age-related maculopathy: pooled findings from the Beaver Dam and Blue Mountains Eye Studies. Ophthalmology. 2003; 110(10):1960-1967.

34. Tomany SC, Cruickshanks KJ, Klein R, Klein BE, Kundtson MD. Sunlight and the 10 - year incidence of age-related maculopathy: the Beaver Dam Eye Study. Arch Ophthalmol. 2004;122(5):750-757.

35. Cruickshanks KJ, Klein R, Klein BE, Nondahl DM. Sunlight and the 5 -year incidence of early age-related maculopathy: the Beaver Dam Eye Study. Arch Ophthalmol. 2001;119(2):246-250.
36. Government of Nepal, National Planning Commission Secretariat, Central Bureau of Statistics. Population Monograph of Nepal. Vol. 2. Thapathali, Kathmandu: Government of Nepal; 2014:230.

37. Bennett S, Woods T, Liyanage WM, Smith DL. A simplified general method for cluster sample surveys in developing countries. World Health Stat Q. 1991;44(3):98-106.

38. ICD-10. International Statistical Classification of Diseases and related health problems. 10th edition, Geneva: World health organization 1992.

39. Bird AC, Bressler NM, Bressler SB, et al. An international classification and grading system for age-related maculopathy age-related macular degeneration. The International ARM Epidemiological Study Group. Surv Ophthalmol. 1995;39(5):367-374.

40. American Academy of Ophthalmology. Age-related macular degeneration and other causes of choroidal neovascularization. Retina Vitreous. 2013-2014; Course 12:55-88.

41. World Health Organization. Report of World Health Organization/ International Diabetes Federation Consultation. Definition and Diagnosis of Diabetes Mellitus and Intermediate Hyperglycaemia. Geneva: World Health Organization; 2006:1-50.

42. Ministry of Health (HMG). Health Sector Strategy: An Agenda for Change (Reform). Kathmandu, : His Majesty Government, Nepal. 2002.

43. Kawasaki R, Wang JJ, Aung T, et al; Singapore Malay Eye Study Group. Prevalence of age-related macular degeneration in a Malay population: the Singapore Malay Eye Study. Ophthalmology. 2008;115(10): $1735-1741$.

44. Kawasaki R, Yasuda M, Song SJ, et al. The prevalence of age-related macular degeneration in Asians: a systematic review and meta-analysis. Ophthalmology. 2010;117(5):921-927.

45. Klein R, Klein BEK, Moss SE. Relation of smoking to the incidence of age-related maculopathy. The Beaver Dam Eye Study. Am J Epidemiol. 1998;147(2):103-110.

46. Erke MG, Bertelsen G, Peto T, Sjolie AK, Lindekleiv H, Njolstag I. Prevalence of age-related macular degeneration in elderly Caucasians. The Tromso Eye Study. Ophthalmology. 2012;119(9):1737-1743.

47. Age-Related Eye Disease Study Research Group. Risk factors for the incidence of advanced age-related macular degeneration in the Age-Related Eye Disease Study (AREDS) AREDS Report No. 19. Ophthalmology. 2005;112(4):533-539.

48. Wang JJ, Mitchell P, Smith W. Refractive error and age-related maculopathy: the Blue Mountains Eye Study. Invest Ophthalmol Vis Sci. 1998;39(58):2167-2171.

49. Thapa R, Bajimaya S, Paudyal G, et al. Population awareness of diabetic eye disease and age related macular degeneration in Nepal: the Bhaktapur Retina Study. BMC Ophthalmol. 2015;15:188.

50. Ho L, Boekhoorn SS, Liana, et al. Cataract surgery and the risk of aging macula disorder: the Rotterdam Study. Invest Ophthalmol Vis Sci. 2008;49(11):4795-4800.

51. Lavanya R, Kawasaki R, Tay WT, et al. Hyperopic refractive error and shorter axial length are associated with age-related macular degeneration: the Singapore Malay Eye Study. Invest Ophthalmol Vis Sci. 2010; 51(12):6247-6252.

52. Thapa S, Berg RVD, Khanal S, et al. Prevalence of visual impairment, cataract surgery, and awareness of cataract and glaucoma in Bhaktapur district of Nepal. BMC Ophthalmol. 2011;11:2.
Clinical Ophthalmology

\section{Publish your work in this journal}

Clinical Ophthalmology is an international, peer-reviewed journal covering all subspecialties within ophthalmology. Key topics include: Optometry; Visual science; Pharmacology and drug therapy in eye diseases; Basic Sciences; Primary and Secondary eye care; Patient Safety and Quality of Care Improvements. This journal is indexed on Submit your manuscript here: http://www.dovepress.com/clinical-ophthalmology-journal
Dovepress

PubMed Central and CAS, and is the official journal of The Society of Clinical Ophthalmology (SCO). The manuscript management system is completely online and includes a very quick and fair peer-review system, which is all easy to use. Visit http://www.dovepress.com/ testimonials.php to read real quotes from published authors. 